\title{
EER Improvement for Room Air-Conditioners in Saudi Arabia
}

\author{
Abdullah M. Al-Shaalan \\ Al-Zamil Chair for Electricity Conservation, College of Engineering, King Saud University, Riyadh, KSA \\ Email: Shaalan@ksu.edu.sa
}

Received September 2, 2012; revised October 5, 2012; accepted October 16, 2012

\begin{abstract}
This paper demonstrates the possibility of achieving a higher Energy Efficiency Ratio (EER) for Room Air Conditioners (RACs) that complies with the Saudi energy efficiency standards and satisfies the energy conservation requirements for the Saudi Building Code (SBC). This study considers several design options for improving the performance and efficiency of the RAC in comparison with a baseline RAC unit manufactured by Al-Zamil Company of Saudi Arabia. These design options include the number of condenser and evaporator rows, fins density, frontal area, compressor types, and refrigerant types. The experimental data obtained is through testing the units in Calorimeter according to standard ASHRAE-16. Also, the uncertainty in measurements and its propagation are included in this study. This paper reports the results of a set of measurements carried out on a modified RAC and compares them with the tested baseline RAC unit at similar load conditions. The experimental results indicate the effectiveness of increasing the number of condenser rows in comparison with other design options considered for achieving higher EER for RACs.
\end{abstract}

Keywords: EER; RAC; Evaporator; Condenser

\section{Introduction}

Several studies have shown how electric peak loads are primarily the result of air conditioning use. Along with lighting and refrigerators, air conditioners rank among the top three huge power users of electricity in households. In fact, peak power load occurs during the summer months as air conditioners offer a more comfortable living environment. Both air conditioner design and the way in which they are activated during hot summer afternoons combine to create serious electric capacity difficulties. In Saudi Arabia, air conditioners are the principal cause of peak electrical demand during hot summer months because the majority of air conditioning systems run on electricity. Indeed, the sweltering heat in the Kingdom, averaging $45^{\circ} \mathrm{C}$, has bolstered the necessity for cooling residential as well as non-residential buildings.

One of the main factors influencing the increased consumption of electricity in the areas of air-conditioning is a significant increase in the number of devices used. So along with the large amount of electrical energy consumed by up to $60 \%$ of the total energy consumption, the growing load in the summer is largely due to population growth and better standards of living, causing the so called problem of peak loads (specifically between one and five in the afternoon during the summer months in the Kingdom). This widespread use of air conditioners in both residential and commercial buildings has increased the consumption of electric power. In order to reduce the use of air conditioning systems to the maximum extent possible, several studies have shown a relationship between appropriate measures to building design and temperature conditions comfortable for humans. However, the rising use of air conditioners has directed many researchers to focus their efforts on improving the Energy Efficiency Ratio (EER) of the device itself.

Since the 1980s, efforts have been undertaken to manufacture more energy efficient cooling systems. Though RAC improvements had originally been motivated by escalating energy costs, more recently, modifications have been driven by an increased awareness of environmental issues. A case in point is the use of R-22 as a refrigerant in air-conditioning equipment. As a hydrochloroflurocarbon (HCFC) it depletes the ozone layer that shields the Earth's surface from strong UV radiation. Thus, most countries have either prohibited or limited the manufacture and use of CFCs due to worries over ozone depletion. More environmentally friendly refrigerants are now available for air conditioners as the production and use of R-22 will be banned by the year 2020 .

Therefore, as electrical energy consumption in Saudi Arabia has been climbing at a fast rate over the last three decades due to rapid economic development, this study discusses and proposes some enhanced techniques and 
fundamental design changes in air conditioning equipment with the goal of improving the ratio of energy efficiency (EER) for RACs. Moreover, this project looks into the efforts and attempts being carried out in the Zamil Chair to investigate and learn about the impact of some of these techniques on the efficiency of specific devices manufactured in the Zamil Air Conditioners Factories in Dammam, especially the most commonly used variety in the Kingdom - the window type.

\section{Review of Existing Works}

The energy efficiency ratio (EER) of the unit depends on the total power usage, as well as the net cooling capacity of the unit. The total power usage includes the compressor, the condenser fan, and the evaporator fan. The EER of the unit can be determined by dividing the net cooling capacity by the measured total input power to the unit [1] The larger the difference between outdoor and indoor temperature sources, the larger the difference in condensing and evaporating temperatures, and consequently the larger the compression work and the lower the EER.

Most of the literature reviewed in this study centers on investigating the potential to improve the energy efficiency of room air-conditioners (RACs) and to recommend policy measures [2]. According to the research conducted by Adnot et al. [2], improving the EER for room air conditioners (RACs) depends on adding refrigerant tube rows as well as modification of coil fin design with respect to air side pattern. This, in effect, will result in increasing the cross flow heat exchange and the increase of contact factor (CF) which will be reflected on increasing the apparatus dew point (ADP). Consequently, there will be a reduction of power consumption for the same air temperature difference.

In another study that focuses on air conditioner usage in China, Jun [3] asserts how air-conditioning consumption dominates in summer in the southern and eastern provinces. Air-conditioning in buildings has been increasing steadily over the past few decades, accounting for nearly $40 \%-50 \%$ of electricity consumption in buildings. In many large cities such as Shanghai, it represents over $40 \%$ of peak load during the hottest hours in summer, presenting a serious challenge to the operational security of the electricity grid. It is expected that by 2009 the energy efficiency ratio (EER) of room air conditioners should increase to 2.9 for the single model and 3.2 for the split model. With China remaining the world's largest producer and exporter of air-conditioners, manufacturing $60 \%$ of global output and accounting for just over 30\% of total global exports, most suppliers will focus their research and development on manufacturing more energyefficient and environmentally friendly models.

In a project undertaken by Faramarzi et al. [4], the au- thors maintain that the objective of this multi-phase, multi-year project is to determine the impact of high ambient temperatures on electric demand, efficiency and cooling capacity of five-ton roof top units (RTUs). They report that the major part of the heat transfer is observed to be achieved by the first row. Especially at low air velocities, the heat transfer capability of the downstream rows is limited. Also lower air-side pressure drop can be achieved by using smaller tubes, which leads to much more compact fin-and-tube heat exchanger designs. The use of less than $7 \mathrm{~mm}$ tube diameters, along with small longitudinal and transverse tube pitches $(12.3 \mathrm{~mm}$ and 21 $\mathrm{mm}$, respectively) has become popular in heat exchangers of room air-conditioners. In addition, heat exchangers have gained in compactness with the use of smaller fin pitches (sometimes lower than $1.3 \mathrm{~mm}$ ) and thinner fins (near $0.1 \mathrm{~mm}$ ).

Jang et al. [5] modulated the cooling capacity in three steps using three compressors, thereby saving energy in the same way as that in the variable speed compressor driven air conditioner. Thus, start-up loss could be minimized as a low thermal load resulted in the compressors not frequently starting and stopping-hence, dramatically reducing energy consumption.

The purpose behind the study made by Stewart [6] was to develop an optimization tool and design guidelines for finned-tube condenser heat exchangers while investigating effects of fin enhancements on system performance. This research has shown that increased air frontal area and decreased tube diameter increases efficiency for a fixed cost condenser coil, as well as thinner fins always being better until structural integrity becomes an issue. Her results show that increasing the heat exchanger cost constraint improves system performance up to a point and then the system performance starts to decline. This is due to the frontal area constraint imposed by packaging considerations causing the coil to increase in depth until the increased flow resistance outweighs the increase in air side surface area.

The research presented by Fridley et al. [7] seeks not only to bring China's standard closer in accord with international standards, but also to bring it into greater accord with China's current domestic situation. Thus, they evaluate the technical feasibility and economic impact of air conditioner energy conservation potential in China. Specifically, their analysis evaluates the feasibility of various technical options to raise air conditioner efficiency; they recognize and discuss several methods in which to improve the performance of the coils. For instance, increasing frontal coil area, tube rows, and fin density, as well as improving tube designs.

In a study that focuses on the air conditioner industry in Malaysia, Mahlia et al. [8] discuss in detail the development of the technical options to be analyzed for in- 
creasing air conditioner efficiency. They conclude that a significant EER improvement could achieved if room air conditioning manufacturers in Malaysia are willing to adopt more efficient design options through improving fin design, tube design and the addition of extra rows of refrigerant tubes.

The objectives of a study conducted by Proctor et al. [9] was to collect data on and analyze the performance of presently manufactured air conditioners operating at high ambient temperatures. The design parameters that affect power draw under these conditions were investigated. Four modified air conditioner designs capable of reducing peak draw by at least 500 watts were created and tested with a computer simulation. The compiled power draw, air flow, and static pressure measurements of residential air handlers taken during nine separate field tests of space conditioning systems in Arizona, California, Florida and Nevada, showed that air handler devices do not meet basic performance standards and that the interactions between components combined to further degrade the overall system efficiency. Their findings support conclusions from previous research in Canada that called for a systems approach to improving air handler efficiency.

\section{Research Objectives}

The objectives of the research are as follows:

1) To provide a better understanding of air conditioner performance on peak;

2) To ensure the effectiveness of air conditioner peak load reduction systems with no compromise to the development or the safety of the device;

3) To focus on raising technical quality that is compatible with Saudi Standards and well-suited to the temperatures prevailing in the Kingdom;

4) To increase energy efficiency for better designed air distribution in rooms.

\section{Research Methodology}

Five different methods are used in this project in order to achieve and develop more economic and energy efficient RACs:

1) A comprehensive review and compliance with the specifications and requirements imposed by the Saudi Arabian Standards Organization (SASO) for safe and efficient room air conditioners (RACs);

2) An intensive assessment of both locally and internationally manufactured RACs for the purpose of collecting information about their design and performance levels in order to evaluate how well they conform to Saudi Standards;

3) A review of relevant literature from other countries as well as an examination of related documents from the
Internet;

4) A practical study, analysis, and testing of RACs in order to reach the levels set forth by the Saudi Standards for the EER.

5) A cooperative collaboration with Zamil Air Conditioners for practical application of research and laboratory testing in order to determine the value of the EER.

\section{Classification Test Conditions to Measure the Cooling Efficiency for Air Conditioners}

\subsection{International Standard (ISO)}

The international standard ISO 5151 specification of reference for many countries in the world has been adopted by many nations to measure the efficiency of energy consumption for air conditioning. This standard has also been subjected to some amendments in order to be more suited to the situations prevailing in some countries with respect to day-to-day temperatures and climate conditions. Table 1 shows these amendments which classify the international standard climatic conditions for measuring the efficiency of cooling in the three temperature zones:

\subsection{The Minimum Value (EER) in the Saudi Arabian Standards}

In order to rigorously impose the policy of conserving energy, the Saudi Government has instructed all air conditioner manufacturers to incorporate Energy Efficiency Ratio (EER) in their cooling systems. Therefore, along with the implementation of the international standard mentioned above, is the application of SASO No. 386 to RACs with a rating of T3. These energy-saving specifications have been incorporated with slight differences in the test methods specified in Standard Arabia SASO 385 for "Methods of Test for Room Air Conditioners".

In accordance with the SASO 2663/2007 Standard for "Energy Labelling and Minimum Energy Performance for Air-Conditioners", which specifies the energy labelling requirements and the Minimum Energy Performance (MEPS) for air conditioners, the minimum energy efficiency ratio (EER) should be 5.4 at room temperature $46^{\circ} \mathrm{C}$ and 7.5 at room temperature $35^{\circ} \mathrm{C}$. Moreover, the standard stipulates that a star rating, between a minimum

Table 1. Global classification of outside temperatures.

\begin{tabular}{ccc}
\hline Classification & $\begin{array}{c}\text { Ambient dry bulb } \\
\text { temp. }{ }^{\circ} \mathrm{C}\end{array}$ & $\begin{array}{c}\text { Ambient wet bulb temp. } \\
{ }^{\circ} \mathrm{C}\end{array}$ \\
\hline $\mathrm{T} 1$ & $35^{\circ} \mathrm{C}$ & $24^{\circ} \mathrm{C}$ \\
$\mathrm{T} 2$ & $27^{\circ} \mathrm{C}$ & $19^{\circ} \mathrm{C}$ \\
$\mathrm{T} 3$ & $46^{\circ} \mathrm{C}$ & $24^{\circ} \mathrm{C}$ \\
\hline
\end{tabular}


of one and a maximum of six (the higher the number of stars, the higher the energy efficiency level), be displayed on the energy label.

\subsection{The Minimum Value of EER for Room Air Conditioners in Saudi Arabia and Other Countries}

Table 2 shows the minimum energy requirements (until 2009) that all air conditioners need to meet for Saudi Arabia and other major countries:

As a way of avoiding unnecessary waste and an attempt to discover new energy saving opportunities, many European nations have adopted new methods in order to lower the energy consumption of air conditioners. Table $\mathbf{3}$ displays some of the approaches put into practice for increasing the efficiency of air conditioners:

\section{Laboratory Experiments}

In collaboration and co-ordination with Zamil Air Conditioners Factories, laboratory tests have been conducted on selected air conditioners based on the recommendations and proposals made by the Author according to the Saudi Standard Specifications. It is to be noted that these tests have been performed in accordance with the SASO Standard Requirements. Accordingly, the following methods have been tested on air conditioners (window type) to assess their effects on improving the value of the EER when applied individually and collectively:

- Increasing the number of rows in each file of the condenser (C) and the evaporator (E);

- Increasing the density of spine fins.

Table 2. EER values for RACs in KSA and other major countries.

\begin{tabular}{cc}
\hline Country & EER (BTU/Wh) \\
\hline Saudi Arabia & 7.5 \\
China & 7.8 \\
Europe & 8.9 \\
Japan & 9.0 \\
United States of America & 9.8 \\
\hline
\end{tabular}

Table 3. Some methods used in Europe to improve the efficiency of RACs and their results.

\begin{tabular}{cccc}
\hline $\begin{array}{c}\text { Ambient } \\
\text { temp. }\end{array}$ & $\begin{array}{c}\text { Max. COP (With } \\
\text { evaporator temp. } \\
\left.\text { Tcold }=66^{\circ} \mathrm{C}\right)\end{array}$ & $\begin{array}{c}\text { Theoretical EER } \\
\text { (EER }=\text { COP } \times \\
3.41)\end{array}$ & $\begin{array}{c}\text { Practical } \\
\text { EER }\end{array}$ \\
\hline $50^{\circ} \mathrm{C}$ & 6.3 & 21.48 & 7.16 \\
$40^{\circ} \mathrm{C}$ & 8.2 & 27.96 & 9.32 \\
$30^{\circ} \mathrm{C}$ & 11.6 & 39.55 & 13.18 \\
\hline
\end{tabular}

- Testing the refrigerant R-407C instead of the refrigerant R-22;

- Testing different types of compressors.

\subsection{The Effect of Increasing the Number of Rows in Each File of the Evaporator (E) and Condenser (C)}

Tests were conducted on samples of air conditioners using the following procedures:

$2 \mathrm{C} \times 3 \mathrm{E}$ (two rows of condensers and three rows of evaporators)

$3 \mathrm{C} \times 2 \mathrm{E}$ (three rows of condensers and two rows of evaporators)

$3 \mathrm{C} \times 3 \mathrm{E}$ (three rows of condensers and three rows of evaporators)

$3 \mathrm{C} \times 4 \mathrm{E}$ (three rows of condensers and four rows of evaporators)

$4 \mathrm{C} \times 3 \mathrm{E}$ (four rows of condensers and three rows of evaporators)

$4 \mathrm{C} \times 4 \mathrm{E}$ (four rows of condensers and four rows of evaporators)

The experimental work is carried out on 1.5-ton units as shown in Table 4 and tabulated in Figure 1. The 1.5

Table 4. The Impact of Increasing the Number of 2 Rows of Tubes in the Evaporator and Condenser on the EER of the Air Conditioner (18000 BTU).

\begin{tabular}{ccccc}
\hline $\begin{array}{c}\text { RAC Unit } \\
\text { type }\end{array}$ & $\begin{array}{c}\text { Baseline } \\
\text { unit }\end{array}$ & $\begin{array}{c}\text { Modified } \\
\text { unit 1 }\end{array}$ & $\begin{array}{c}\text { Modified } \\
\text { unit 2 }\end{array}$ & $\begin{array}{c}\text { Modified } \\
\text { unit 3 }\end{array}$ \\
\hline $\begin{array}{c}\text { Rows } \\
\text { number }\end{array}$ & 2C $\times 2 \mathrm{E}$ & $3 \mathrm{C} \times 2 \mathrm{E}$ & $2 \mathrm{C} \times 3 \mathrm{E}$ & $3 \mathrm{C} \times 3 \mathrm{E}$ \\
$\begin{array}{c}\text { Capacity } \\
\text { (BTU/Hr) }\end{array}$ & 17,517 & 17,911 & 17,655 & 17,958 \\
$\begin{array}{c}\text { EER } \\
\% \text { increase }\end{array}$ & 7.39 & 7.83 & 7.54 & 7.95 \\
$\begin{array}{c}\text { in capacity } \\
\% \text { increase } \\
\text { in EER }\end{array}$ & & $2.25 \%$ & $0.8 \%$ & $2.5 \%$ \\
\hline
\end{tabular}

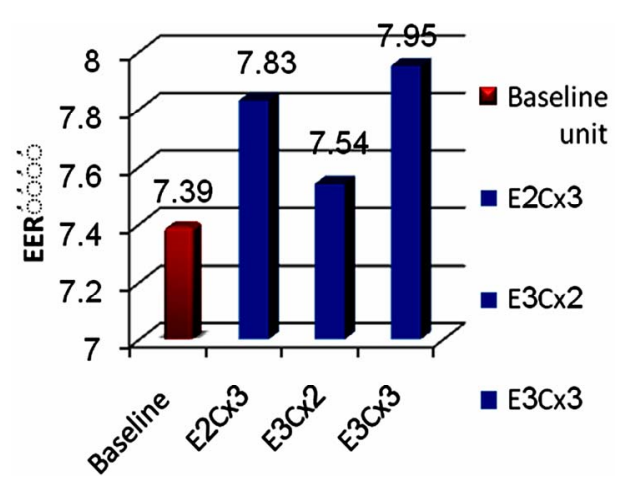

Figure 1. The experimental results indicate the effectiveness of adding extra rows for the condenser in comparison with adding extra rows for the evaporator as shown in Table 5 and tabulated in Figure 2. 


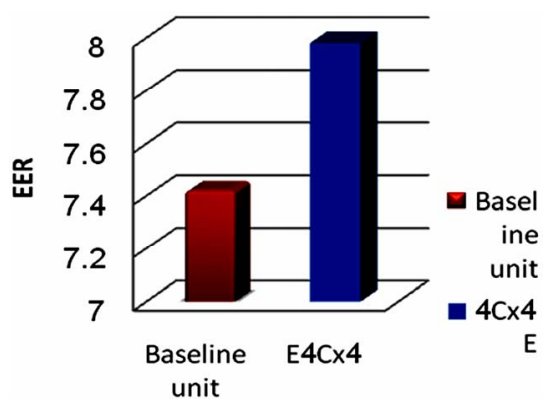

Figure 2. The experimental results indicate that adding extra rows for the condenser increases EER by $7.5 \%$.

Table 5. The effect of adding an extra 3 rows for $(2400$ BTU).

\begin{tabular}{ccc}
\hline RAC unit type & Baseline unit & Modified unit \\
\hline Rows number & $3 \mathrm{C} \times 4 \mathrm{E}$ & $4 \mathrm{C} \times 4 \mathrm{E}$ \\
Capacity (BTU/Hr) & 21,506 & 21,737 \\
EER & 7.42 & 7.98 \\
\% ge increase in capacity & & $1.07 \%$ \\
\% ge increase in EER & & $7.54 \%$ \\
\hline
\end{tabular}

ton baseline unit (Reference unit) has two rows for the condenser rows and two rows for the evaporator rows [2C $\times 2 \mathrm{E}]$. The row combinations include $3 \mathrm{C} \times 2 \mathrm{E}, 2 \mathrm{C} \times$ $3 \mathrm{E}$, and $3 \mathrm{C} \times 3 \mathrm{E}$.

\subsection{The Impact on the EER of the Air Conditioner after Increasing the Density of the FINS on the Condenser and the Evaporator}

Table 6 and Figure 3 show the results of investigating the impact on the energy efficiency ratio of a 24,000 unit air conditioner after increasing the density of the FINS on the condenser and evaporator.

\subsection{The Effect of Using the Cooling Refrigerant R-407 C Instead of the Currently Used Refrigerant R-22 on the Efficiency of RACs}

R-22 has been the refrigerant of choice for air-conditioning systems for more than four decades. However, its harmful effect on the ozone layer resulting in excessive UV levels means the eventual elimination of R-22 over the coming years as part of an agreement to end production of HCFCs. As an alternative, manufacturers of residential air conditioning systems are providing devices that use ozone-friendly refrigerants such as R-407 C. Therefore, Table $\mathbf{7}$ and Figure $\mathbf{4}$ show the EER of RACs after using the gas cooling agent R-407C instead of the traditional agent, R-22:

(The testing is based on ASHRAE-16)
Table 6. The effect of increasing fins density for 2-ton unit.

\begin{tabular}{ccc}
\hline RAC unit type & Baseline unit & Modified unit \\
\hline Fins density & $\begin{array}{c}\bullet \text { Evaporator row fins } \\
\text { density: } 14 \text { fins/inch } \\
\bullet \text { Condenser row fins } \\
\text { density: } 16 \text { fins/inch }\end{array}$ & $\begin{array}{c}\bullet \text { Evaporator row fins } \\
\text { density: } 16 \text { fins/inch } \\
\bullet \text { Condenser row fins } \\
\text { density: } 18 \text { fins/inch }\end{array}$ \\
$\begin{array}{c}\text { Capacity } \\
\text { (BTU/Hr) }\end{array}$ & 22,605 & 23,435 \\
EER & 7.3 & 7.48 \\
$\begin{array}{c}\text { \% ge } \\
\text { increase in } \\
\text { capacity } \\
\text { \% ge }\end{array}$ & & $3.6 \%$ \\
$\begin{array}{c}\text { increase in EER } \\
\% \text { ge }\end{array}$ & & $2.46 \%$ \\
increase in cost & & $1.0 \%$ \\
\hline
\end{tabular}

Table 7. The effect of specific refrigerants on EER.

\begin{tabular}{ccccc}
\hline Refrigerant type & R-22 & R-407 C & R-22 & R-407 C \\
\hline Rows number & $3 \mathrm{E} \times 2 \mathrm{C}$ & $3 \mathrm{E} \times 2 \mathrm{C}$ & $2 \mathrm{E} \times 3 \mathrm{C}$ & $2 \mathrm{E} \times 3 \mathrm{C}$ \\
$\begin{array}{c}\text { Capacity } \\
\text { (BTU/Hr) }\end{array}$ & 17,725 & 16,899 & 17,860 & 17,210 \\
$\quad \mathrm{EER}$ & 7.79 & 7.16 & 8.12 & 7.48 \\
$\begin{array}{c}\text { \% ge reduction in } \\
\text { capacity }\end{array}$ & & $4.66 \%$ & & $4.7 \%$ \\
$\begin{array}{c}\text { \% ge reduction in } \\
\text { EER }\end{array}$ & & $8.08 \%$ & & $7.9 \%$ \\
\hline
\end{tabular}

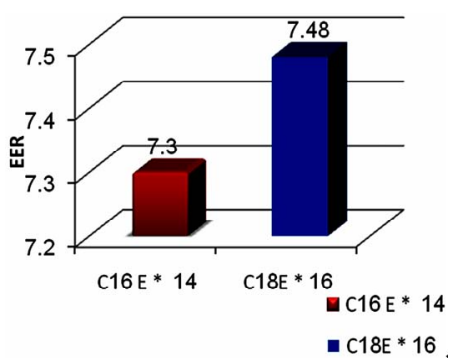

Figure 3. The experimental results indicate that increasing the fins density has limited effect on the EER.

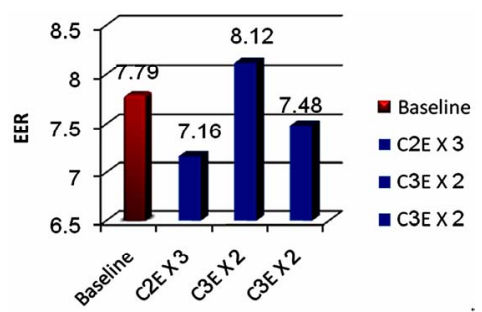

Figure 4. The experimental results on 1800 BTU unit indicate that using the refrigerant $R-407 \mathrm{C}$ instead of $\mathrm{R}-22$ has negative effect on the EER. Therefore, $R-407 \mathrm{C}$ is not an adequate replacement for $\mathrm{R}-22$, as it leads to a decline in the value of the EER of the air conditioner. 


\subsection{The Effect of Using Different Compressors on the Efficiency of RACs}

Air conditioners fitted with a reciprocating compressor are tested and found to be less energy efficient as the ones tested with a rotary compressor. The latter is a comparatively superior type of compressor over the conventional reciprocating type, because it compresses air by centrifugal action of a high-speed impeller in a confined space. This method reduces the loss in pressure of the refrigerant thereby rendering the cooling device more energy efficient. The results are given in Table 8 and Figure 5.

\subsection{The Effect of Adding Extra Rows and Fins on the Evaporator and Condenser Coils}

The impact of integration on the proportion of energy efficiency of an 18,000 BTU [4] air conditioner surges when the number of rows and feathers in both evaporator and condenser are increased. The results of this comparison are given in Table 9 and Figure 6:

The results for increasing the number of rows and feathers in both the evaporator and the condenser are as follows:

- Increasing the number of rows has a clear impact on efficiency, where the value of EER rises by $7.57 \%$.

- Increasing the number of feathers in both the evaporator and the condenser has no effect on the efficiency for the 18,000 air conditioner unit.

Table 8. A comparison between two types of compressors based on ASHRAE-16.

\begin{tabular}{ccc}
\hline Compressor type & Rotary & Reciprocating \\
\hline Rows number & $3 \mathrm{E} \times 2 \mathrm{C}$ & $3 \mathrm{E} \times 2 \mathrm{C}$ \\
Capacity (BTU/hr) & 17,655 & 17,639 \\
EER & 7.54 & 7.46 \\
\hline
\end{tabular}

Table 9. The effect of adding extra rows and fins for 1.5-ton unit.

\begin{tabular}{|c|c|c|c|}
\hline RAC unit type & Baseline unit & Modified unit 1 & Modified unit 2 \\
\hline $\begin{array}{l}\text { Coil Number } \\
\text { \& Fins Density }\end{array}$ & $\begin{array}{l}2 \mathrm{E} \& 14 \\
\text { fins/inch } \\
2 \mathrm{C} \& 16 \\
\text { fins/inch }\end{array}$ & $\begin{array}{l}\text { 3E \& } 14 \\
\text { fins/inch } \\
\text { 3C \& } 16 \\
\text { fins/inch }\end{array}$ & $\begin{array}{l}\text { 3E \& } 16 \\
\text { fins/inch } \\
\text { 3C \& } 18 \\
\text { fins/inch }\end{array}$ \\
\hline $\begin{array}{l}\text { Capacity } \\
\text { (BTU/Hr) }\end{array}$ & 17,517 & 17,958 & 17,904 \\
\hline EER & 7.39 & 7.95 & 7.96 \\
\hline $\begin{array}{l}\text { \% ge increase } \\
\text { in capacity }\end{array}$ & & $2.5 \%$ & $2.2 \%$ \\
\hline $\begin{array}{l}\text { \% ge increase } \\
\text { in EER }\end{array}$ & & $7.57 \%$ & $7.57 \%$ \\
\hline Added cost & & $62 \mathrm{SR}$ & $67 \mathrm{SR}$ \\
\hline
\end{tabular}

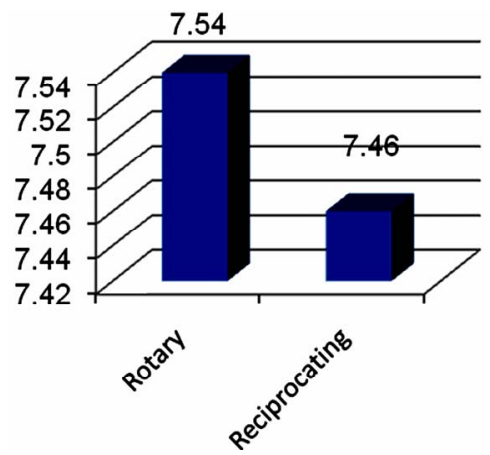

Figure 5. The experimental results on 1.5-ton unit indicate that using a rotary compressor has a positive effect on EER.

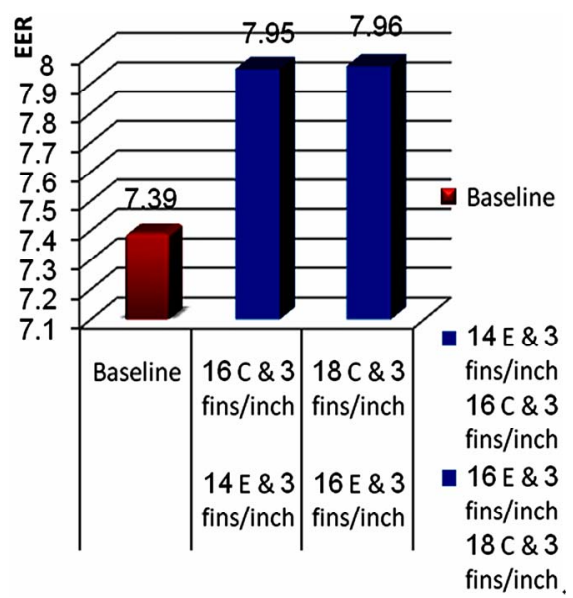

Figure 6. The experimental results on the 1.5-ton unit indicate that while adding the extra fins has little effect on the unit's EER, the addition of extra rows for the evaporator coil and for the condenser coil increases EER.

\section{The Results of the Study}

1) The EER value increased by $6 \%$ with a single row of condenser ( $\mathrm{C}$ to 18,000 units).

2) The EER value increased by $2 \%$ with a single row of the evaporator (air conditioner to 18,000 units).

3) The EER value increased by $7.5 \%$ when a single row was added to the condenser and evaporator (air conditioner to 18,000 units).

4) The EER value increased by $7.5 \%$ with the inclusion of a single row of a condenser (air conditioner to 24,000 units).

5) The EER value increased by nearly $2.5 \%$ after increasing the density by 2 feathers (feather/inch) in both the evaporator and the condenser (air conditioner to 24,000 units). This is the maximum available for this air conditioner.

6) The EER value increased by $1.07 \%$ when using a rotary compressor rather than a reciprocating compressor; this percentage will increase to $4.05 \%$ when one row is added to the condenser. 
7) The EER value is raised by $7.57 \%$ after increasing one row in each of the condenser and the evaporator. Moreover, the density of feathers in the condenser was increased to 18 feathers/inch instead of 16 feathers/inch while the density of the feathers in the evaporator was also increased to 16 feathers/inch instead of 14 feathers/inch.

8) The decline of $7.9 \%$ in the EER value when using Freon R-407 C instead of Freon R-22.

\section{Conclusions and Recommendations}

Energy Efficiency Ratio measures the cooling efficiency of the air conditioner compared to the power it consumes. It is the ratio of the cooling capacity in BTU/hr to its electricity consumption in watts. Thus, the higher EER of a model, the more energy efficient it is. Hence, the higher the ratio, the less the unit will cost to operate; increasing the value of the cooling capacity while at the same time reducing the consumption of electricity relies on many different components, which vary in their level of impact. This study has tested the best methods for increasing the EER of RACs and discovered that the most important one involved the cooling coils, which have been highlighted in this study. Below are some recommendations and strategies drawn from the results of this study for improvements in energy efficiency:

1) Increasing the cooling capacity can be achieved by increasing the number of the rows of tube files in both the evaporator and the condenser. However, the increase in the number of rows in the condenser has a greater impact on the value of the EER compared to an increase in the number of rows in the evaporator. But there are limits to intensifying the number of rows, as this leads to an increased surface area that produces a higher air flow; if the air is traveling too fast across the coil then these results in insufficient heat transfer which causes a drop in air pressure.

2) The design of the feathers (FINS) themselves has a more positive impact on the efficiency of the air conditioner as compared to an increase in their density (feather/inch). Indeed, this study has found that there are limits which must not be exceeded with regard to increasing the density of the fins. As a result, it is recommended that no more than a density of 14 feathers per inch be installed.

3) The higher the quality of the refrigerant, the higher the cooling capacity of the device .Though R-22 gives a better EER than R-407 C, the former will cease to be manufactured by the year 2020 .

4) The use of a rotary compressor is less expensive and has a more positive impact on the efficiency of the air conditioner than a reciprocating one which is more expensive and requires more maintenance. However, the latter does have a few distinguishing features that set it apart from the former type like, a lower rise in temperature and a longer operating life.

5) The cooling capacity of the file is directly proportional to the speed of the air inside the file. But there are limits to this speed, as the high speeds can lead to negative consequences such as falling air pressure, an increase in the level of noise, and an increase the coefficient of the path Lateral (BPF).

In light of the results obtained from this study, it has been observed that the increased Energy Efficiency Ratio (EER) for RACs resulting from the increased number in the rows of tubes, though not substantially high, was an indication of the possibility for improving the efficiency ratio of energy to the value of acceptable and good. Therefore, more substantial advancements in energy consumption may be achieved by modifying the design of an air conditioner cover and base in order to allow the addition of two or three rows of tubes in a condenser as well as an additional two rows to a file evaporator.

\section{Acknowledgements}

The Author wishes to express his appreciation and gratitude for the support received from the Al-Zamil Chair during the performing of this study.

\section{REFERENCES}

[1] ANSI/ARI Standard 210/240, "Standard in Unitary Air Conditioning and Air Source Heat Pump Equipment,” Air Conditioning and Refrigeration Institute, Michigan, 2003.

[2] J. Adnot, M. Orphelin, C. Lopes and P. Waide, "Limiting the Impact of Increasing Cooling Demand in the European Union: Results from a Study on Room Air-Conditioner Energy Efficiency," Proceedings: 2000 ACEEE Summer Study on Energy Efficiency in Buildings, Washington, pp. 1-12.

[3] J. Li, "Bilateral Collaboration on Energy Efficiency in Buildings,” Institute du Development Durable et des Relations Internationals (IDDRI), Paris, February 2008.

[4] R. Faramarzi, et al., "Performance Evaluation of Typical Five-Ton Roof Top Air Conditioning Units under High Ambient Temperatures," Refrigeration and Thermal Test Center, Southern California Edison, 2004.

[5] J. I. Jang and S. Jin, "An Experimental Comparison of Energy Efficiency Indicators, EER and SEER in Residential Air Conditioners,” LG Electronics, London, 2006.

[6] S. W. Stewart, "Enhanced Finned-Tube Condenser Design and Optimization,” Ph.D. Dissertation, Georgia Institute of Technology, Atlanta, 2003.

[7] D. Fridley, G. Rosenquist, J. Lin, A. X. Li, D. G. Xin and J. H. Cheng, "Technical and Economic Analysis of Energy Efficiency of Chinese Room Air Conditioners," LBNL-45550 US Department of Energy under Contract No. DE-AC03-76SF00098, 2001. 
[8] T. M. I. Mahlia and H. H. Masjuki, "Cost-Efficiency Analysis in Support of Energy Efficiency Standards for Room Air Conditioners,” Department of Mechanical Engineering, University of Malaya, Kuala Lumpur, 2002.

[9] J. P. Proctor, T. D. Downey, C. Boecker, Z. Katznelson,
G. Peterson and D. O’Neal, "Investigation of Peak Electric Load Impacts of High SEER Residential HVAC Units,” Pacific Gas and Electric Company Research and Development Department, San Ramon, 1996. 